Proceedings

\title{
Analysis of land development potential using remote sensing for Kangra District, Himachal Pradesh, India
}

1 University Institute of Architecture, Chandigarh University, NH-95, Ludhiana - Chandigarh State Highway, Punjab 140413, India; ar.shrutisidhu@gmail.com

* Correspondence: ar.shrutisidhu@gmail.com

\begin{abstract}
Kangra is one of the twelve districts in the state of Himachal Pradesh, India. It has the geographical area of 5,739 sq. km. which becomes 7088.43 sq. $\mathrm{km}$ when the terrain is also considered. It is further divides into 21 sub-districts (or Tehsils). For this study the tehsils of Kangra district are compared using a Land development index formulated with relation to the land use land cover characteristics to finally evaluate their individual development potential. The land use land cover (LULC) was analyzed using the 2015-16 data as prepared by the National Remote Sensing Centre, Hyderabad from the Multi-temporal satellite data from Resourcesat-2 LISS III. The topographical maps were also created using the State's Bhuvan (Indian Geoportal of ISRO) map along with Google maps. The land covers were analyzed under the categories of forest cover, non-agricultural uses, barren/cultivable land, grass/grazing, wastelands, net sown area - agricultural land and misc. land cover. The predominant landcover for the district is forest cover (34.3\%) followed by agricultural and crop land (29.5\%). According to the comparative study Multan, Khudian, Borah and Jaswan tehsils show the lowest level of development with the maximum wasteland areas and lowest agricultural land while that Indora, Nagrota Bhagwan, Dehra Gopipur, Nurpur, Jawali, Harchakian, Dharamshala and Jawalamukhi show the highest level of development with contributing factors of higher built-up land and lower grazing land cover. The tehsils Shahpur, Kangra, Palampur, Thural, Fatehpur, Rakkar, Dhira, Jaisinghpur and Baijnath show an average level of development with varying figures of land use land cover.
\end{abstract}

Citation: Sidhu, S., 2022, Analysis of land development potential using remote sensing for Kangra District, Himachal Pradesh, India. SUPTM 2022 conference proceedings sciforum054198.

https://doi.org/10.31428/10317/10489

Publisher's Note: UPCT and Sciforum stays neutral with regard to jurisdictional claims in published maps and institutional affiliations.

Copyright: (c) 2022 by the authors. Submitted for possible open access publication under the terms and conditions of the Creative Commons Attribution (CC BY) license (https://creativecommons.org/license s/by/4.0/).
Keywords: Land use land cover (LULC), land development, GIS, Kangra district

\section{Introduction} factors aligned with the socio-economic and physical development of a region [1]. This can be observed through changes in the density and direction of built-up and non-builtup land through time. The objective of this study is to formulate a grading criterion to quantify development in a region in relation with its existing land use land cover. The area identified for this study is the district Kangra in Himachal Pradesh, India. Its sub districts are evaluated for their contribution towards the development for the district as a whole. Development in a hilly area is governed through patterns of land management which need to be synchronous with the ecological footprint and economic activities, that primarily happen to be agrarian [2]. LULC profiles related with these goals are used for the analysis in this paper.

\section{Area of Study}

Kangra is one of the 12 districts of Himachal Pradesh, India. It is located in the western region of the state between $31^{\circ} 21^{\prime}$ to $32^{\circ} 59^{\prime} \mathrm{N}$ latitude and $75^{\circ} 47^{\prime} 55^{\prime \prime}$ to $77^{\circ} 45^{\prime} \mathrm{E}$ longitude and covers an area of 5739 sq. km. [3]. It has 21 sub-districts with a population of
Land Use Land Cover (LULC) classifications have been observed to impact various 
$68,64,602$ and a density of 123 persons [4]. The reason for selecting Kangra district for this study is based on the benefits of both its geographical location within the state and its varying topography. It is located centrally on the western side of Himachal Pradesh, consists of its summer capital city of Kangra and the maximum population of all the districts. Topographically, towards the southern and south-western region (Indora and Fatehpur) the land is predominantly flat while the height increases towards the northeastern parts (Baijnath and Multhan) [5].

\section{Data Collection and Analysis}

The research is based on the Land Use Land Cover data for Kangra district for 20152016 along with the administrative boundaries. The data for previous years was not included in this study. The primary source of Land Use Land Cover data used was as prepared by the National Remote Sensing Centre, Hyderabad using the multi-temporal satellite data from Resourcesat-2 LISS-III [6]. ArcGIS software was used to analyze the data to further achieve the objectives of the study.

\subsection{Land Use Land Cover data}

The classification of land use land cover data [7] used for the study are broadly divided into forest cover, non-agricultural uses, barren or uncultivable land, grass or grazing land, wastelands, net sown area and miscellaneous landcover. The overall distribution within the district is as shown in Table 1.

Table 1. Land Use Land Cover Classification of Kangra District (2015-16) [8]

\begin{tabular}{ccc}
\hline Land Use & Area (in Hectares) & Percentage (\%) \\
\hline Forest Cover & $2,23,738$ & 39 \\
Non-agricultural uses & 71,661 & 12.5 \\
Barren or uncultivable land & 43,799 & 7.6 \\
Grass or Grazing land & $60,391.3$ & 10.5 \\
Wastelands & $26,894.4$ & 4.7 \\
New sown area/Agricultural land & $1,22,216$ & 21.3 \\
Miscellaneous land cover & $25,275.9$ & 4.4 \\
\hline TOTAL & $5,73,975.6$ & 100 \\
\hline
\end{tabular}

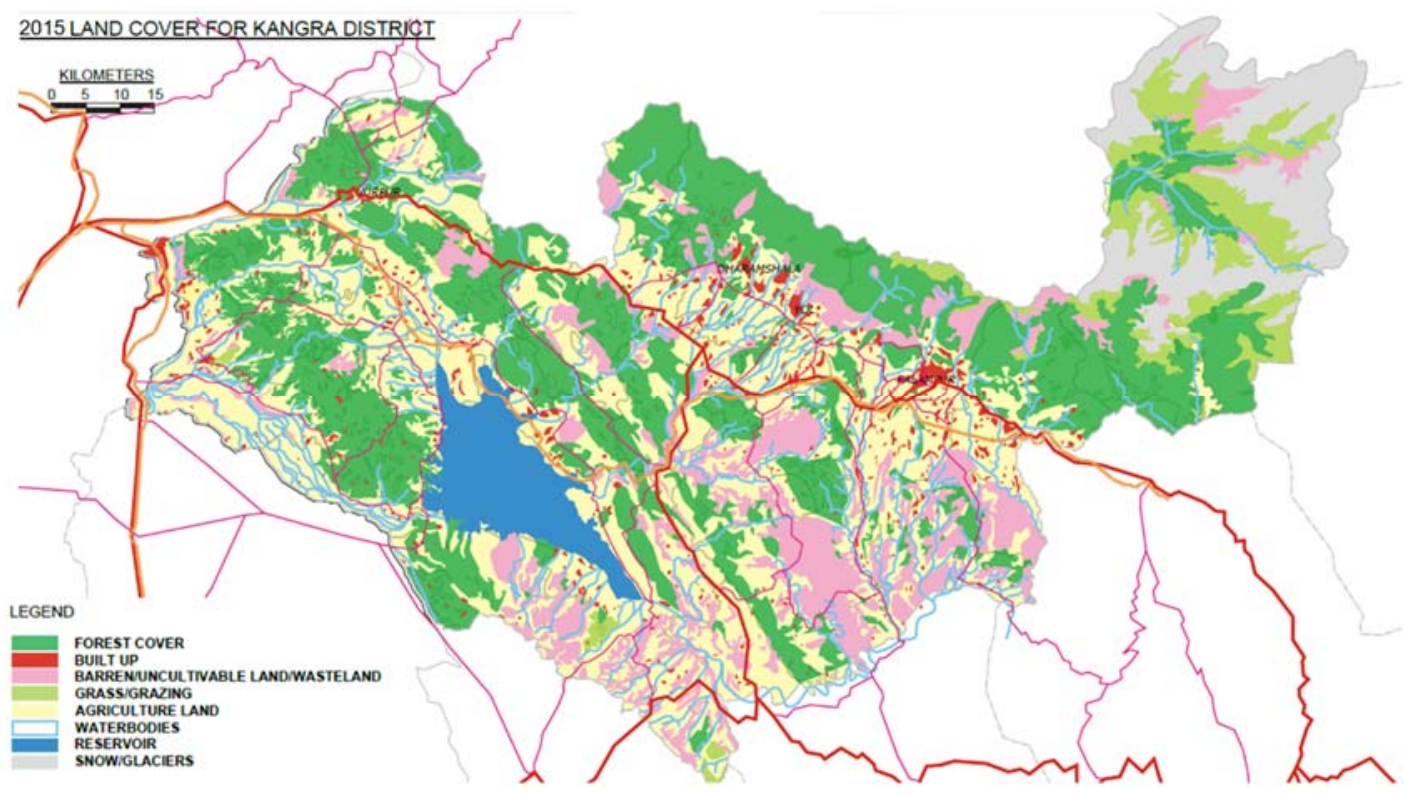

Figure 1. Land Cover Map for Kangra District (Source: Drawn by Author, data originally sourced from bhuvan.nrsc.gov.in) [9] 


\section{Results and Discussions}

For the purpose of a comparative analysis between the sub-districts of Kangra, a composite index for development was formulated based on their LULC. The sub-districts/tehsils were given credits from 'least to most developed' ranging between 1 to 21 respectively. The categorization of the different land cover for a given development index is based on the correlation between the land cover and development. It is observed that the categories a, c, d, e, and g have a negative correlation with the values (and percentages) increasing inversely in relation to each other while categories $b$ and $f$ have a positive correlation with the values increasing synchronously. Assessing the land use-land cover on the sub-districts with the development correlation the formulated composite index can be seen in Table 2.

a. Forest cover and development: A negative correlation exists between the extent of forest cover and development in the region, with an increasing forest cover referring to lesser development.

b. Non-agricultural uses and development: A positive correlation exists between the extent of land devoted to non-agricultural uses and development in the region, with an increased use in the form of built-up areas directly referring to increased development.

c. Barren/Uncultivable land and development: A negative correlation exists between the land in a barren or uncultivable state and development in the region, with an increase in such land would directly refer to land which is not usable for development.

d. Grass land or grazing land and development: A negative correlation exists between grass or grazing land and development of the region, referring to an increase in such type of land which is not being used for development; directly implying lesser development in the region.

e. Wasteland and development: A negative correlation exists between wasteland and development of the region, with such land either being available for cultivation but being kept empty or unused for a span of time referring to lesser contribution to development of the region.

f. Agricultural land and development: A positive correlation exists between the new sown area and development of the region, referring to an increase in use of land for agricultural purposes that would reflect an increase in development of the region.

g. Miscellaneous land cover and development: A negative correlation exists between miscellaneous land cover and development of the region, with land being used for purposeless uses or encroached upon reflecting a decreased development in the region.

Table 2. Formulated Land Development Index of the Sub-districts

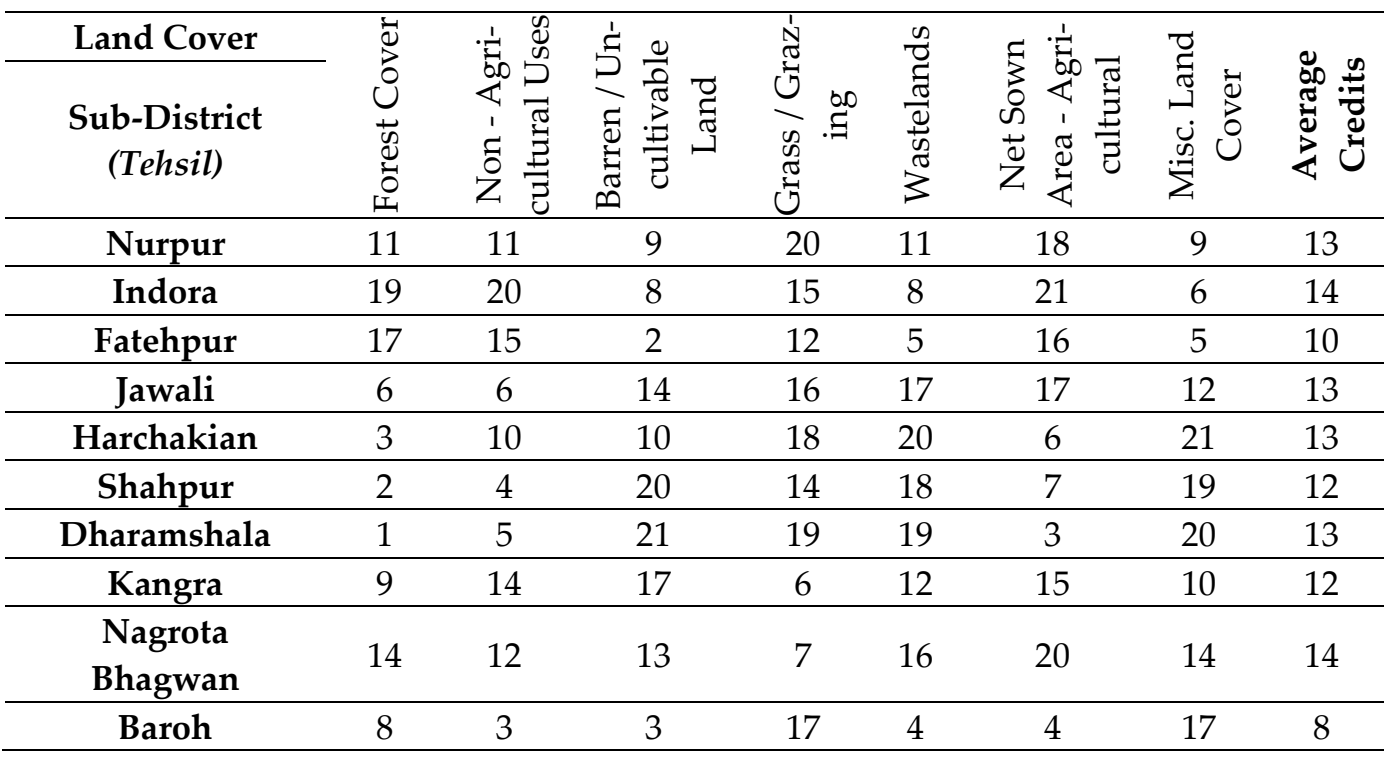




\begin{tabular}{ccccccccc}
\hline Dehra Gopipur & 20 & 21 & 11 & 11 & 13 & 2 & 18 & 14 \\
\hline Jawalamukhi & 18 & 19 & 5 & 13 & 6 & 19 & 8 & 13 \\
\hline Jaswan & 10 & 8 & 12 & 4 & 2 & 5 & 15 & 8 \\
\hline Rakkar & 16 & 16 & 1 & 21 & 3 & 8 & 3 & 10 \\
\hline Khundian & 15 & 9 & 15 & 9 & 1 & 10 & 1 & 9 \\
\hline Thural & 13 & 18 & 4 & 5 & 7 & 13 & 16 & 11 \\
\hline Dhira & 12 & 13 & 16 & 3 & 10 & 11 & 7 & 10 \\
\hline Jaisinghpur & 21 & 17 & 6 & 2 & 9 & 12 & 2 & 10 \\
\hline Palampur & 7 & 7 & 19 & 8 & 15 & 14 & 13 & 12 \\
\hline Baijnath & 5 & 2 & 18 & 10 & 14 & 9 & 11 & 10 \\
\hline Multhan & 4 & 1 & 7 & 1 & 21 & 1 & 4 & 6 \\
\hline
\end{tabular}

\section{Conclusion}

The study was conducted as per the LULC classifications by the National Remote Sensing Centre (NRSC), Hyderabad and further evaluated using the formulated land development index. Based on the calculations, it can be seen that Indora, Nagrota Bhagwan and Dehra Gopipur are the most developed sub-districts with the average credit of 14, followed by Nurpur, Jawali, Harchakian, Dharamshala and Jawalamukhi with the average credit of 13 . These may be considered the sub-districts with 'high development'. The sub-districts with a considered 'average development' are Shahpur, Kangra and Palampur with the average credit of 12, Thural with the average credit of 11 and Fatehpur, Rakkar, Dhira, Jaisinghpur and Baijnath with the average credit of 10 . The sub-districts with a considered 'low development' are Khudian with average credit of 9, Borah and Jaswan with average credit of 8 and Multhan with average credit of 6 . Similar studies can be conducted on the state and country level.

Funding: This research received no external funding.

Acknowledgments: Author has used the Land Use Land Cover information on her research work from Natural Resources Census Project of National Remote Sensing Centre (NRSC), ISRO, Hyderabad, India.

Conflicts of Interest: The author declares no conflict of interest.

\section{References}

[1] Shaghla Parveen, Jasmeen Basheer and Bushra Praveen. (2018); A LITERATURE REVIEW ON LAND USE LAND COVER CHANGES. Int. J. of Adv. Res. 6 (Jul). 1-6] (ISSN 2320-5407). DOI: 10.21474/IJAR01/7327

[2] Special Area Development Programmes, 8th Five Year Plans, Planning Commission, Government of India

[3] Statistical Abstract of Himachal Pradesh, Department of Economic and Statistics, Government of Himachal Pradesh, Shimla

[4] Census of India, 2011

[5-9] NRSC (2019), Land Use / Land Cover database on 1:50,000 scale, Natural Resources Census Project, LUCMD, LRUMG, RSAA, 